\title{
Кислин Константин Борисович
}

\section{ОСОБЕННОСТИ ИСПОЛЬЗОВАНИЯ АНТИЧНЫХ СЮЖЕТОВ В СРЕДНЕВЕКОВЫХ ЕХЕМРLА}

В статье рассматривается специфика использования античных сюжетов в средневековых западноевропейских сборниках для проповеди - exempla. Делается вывод о том, что античные сюжеты не столько переосмысляются авторами средневековых сборников, сколько используются в качестве наглядного нравоучительного материала наряду с другими сюжетами, такими как анекдоты из повседневной жизни, с целью обеспечения большей эфффективности того или иного морального поучения. Отдельное внимание уделяется проблеме генезиса символического мировосприятия в Средние века.

Адрес статьи: www.gramota.net/materials/9/2019/11/41.html

\section{Источник}

\section{Манускрипт}

Тамбов: Грамота, 2019. Том 12. Выпуск 11. С. 215-219. ISSN 2618-9690.

Адрес журнала: www.gramota.net/editions/9.html

Содержание данного номера журнала: www.gramota.net/materials/9/2019/11/

\section{( ) Издательство "Грамота"}

Информация о возможности публикации статей в журнале размещена на Интернет сайте издательства: www.gramota.net Вопросы, связанные с публикациями научных материалов, редакция просит направлять на адрес: hist@gramota.net 


\title{
Философия религии и религиоведение
}

\author{
Philosophy of Religion and Religious Studies
}

УДК $1 ; 2 ; 25: 252.3$

https://doi.org/10.30853/manuscript.2019.11.41

Дата поступления рукописи: 28.08.2019

В статье рассматривается специфика использования античных сюжетов в средневековых западноевропейских сборниках для проповеди - ехетрla. Делается вывод о том, что античные сюжеты не столько переосмысляются авторами средневековых сборников, сколько используются в качестве наглядного нравоучительного материала наряду с другими сюжетами, такими как анекдоты из повседневной жизни, с иелью обеспечения большей эффективности того или иного морального поучения. Отдельное внимание уделяется проблеме генезиса символического мировосприятия в Средние века.

Ключевые слова и фpaзы: exempla; средневековая картина мира; христианская проповедь в Средние века; рецепция античной мифологии; монашеские ордена.

Кислин Константин Борисович

Санкт-Петербургский государственный университет

kislin_k_rel@mail.ru

\section{ОСОБЕННОСТИ ИСПОЛЬЗОВАНИЯ АНТИЧНЫХ СЮЖЕТОВ В СРЕДНЕВЕКОВЫХ ЕХЕМРLА}

Статья подготовлена в рамках проекта РФФИ № 18-011-01123 «Проблема сопряжения морали и религии в эпикурейской и стоической философии: сравнительный анализ полемического дискурса».

Цель данной статьи состоит в том, чтобы определить специфику восприятия античных сюжетов в средневековых сборниках exempla. В соответствии с поставленной целью решаются следующие задачи: обратить внимание на философские корни символического восприятия действительности в Средние века; рассмотреть сборники ехеmpla в контексте средневекового мировосприятия; указать на особенности использования античного материала в средневековой проповеди.

Актуальность обозначенной темы связана с тем, что изучение средневековых нравоучительных сборников для проповеди exempla (ед. ч. exemplum - лат., букв. «пример») в настоящее время вызывает большой интерес у ученых-медиевистов, как отечественных (В. В. Смирнова, Л. Г. Хорева, А. В. Топорова и др.), так и зарубежных (Стефано Мула, Мари-Анн Поло де Болье и др.). Исследования в данной области имеют большое значение для понимания специфики отношения к античному наследию в Средние века.

Научная новизна данной работы обусловлена рассмотрением особенностей отношения к античным сюжетам в сборниках ехерmla через призму средневекового мировосприятия. Специфика рецепции античного материала в сборниках exempla представлена в статье в контексте традиции аллегорической трактовки текста, берущей начало еще в античную эпоху, которая была продолжена крупнейшими христианскими мыслителями.

Традиция аллегорической трактовки текста берет начало еще в античную эпоху: критики Гомера - Феоген Регийский, Ксенофан и др. - предлагали аллегорически воспринимать богов, описанных в «Одиссее» и «Илиаде». Стоик Корнут - автор трактата «Греческое богословие» (“Theologiae Graecae Compendium”) - трактует образ Зевса таким образом: «Подобно человеческой душе, управляющей нами, есть душа и у миропорядкакосмоса, связывающая и удерживающая его. Имя душе этой - Зевс» [3, с. 20]; и далее, толкуя образ Геракла: «Геракл представляет собой разумное основание, придающее естеству незыблемость и мощь, делающее его непобедимым, обеспечивающее всю природу твердостью» [Там же, с. 59]. Ориген - основатель ранней христианской герменевтики - выделял три возможные степени трактовки текста (три «пласта» его смысла): исторический - объективное, буквальное понимание текста; душевный - интерпретация текста с точки зрения человеческого восприятия смысла, так называемый «явный смысл»; духовный - то есть «тайный» смысл текста, постичь который возможно исключительно при помощи веры и откровения [5]. Один из самых влиятельных христианских мыслителей - Аврелий Августин - в своем трактате «Христианская наука» постулировал разделение «вещи» и «знака»: «вещь», согласно его учению, познается через «знак» [1]. 
Важнейшим философским процессом, повлиявшим на формирование символического подхода к пониманию действительности в Средние века, становится полемика номиналистов и реалистов. Под влиянием реализма, утверждающего наличие универсалий, существующих «до вещи», в этот период складывается представление о том, что за каждым феноменом действительности стоит «высшая сущность»; что каждый объект, сюжет или факт материального мира отсылает разум человека к некой трансцендентной, находящейся вне времени и пространства «идее» этой вещи, объекта или факта.

Таким образом, в своем труде «Символическая история европейского Средневековья» М. Пастуро замечает: «Средневековое мышление по аналогии старается установить связь между явным и скрытым, что присутствует в этом мире, и тем, что находится среди вечных истин мира потустороннего» [6, с. 14].

С X века широкое распространение в средневековой Европе получают этимологические словари, авторы которых пытаются добраться до онтологической сути того или иного слова путем различного рода сопоставлений и спекуляций. М. Пастуро приводит в пример негативное отношение к дереву орех (лат. пих) на том основании, что его название созвучно латинскому глаголу «вредить» (nocere) (та же самая ситуация происходит со словом яблоко: malus - яблоко и mal - зло, лат.) [Там же, с. 12].

Важнейшей составляющей каждого отдельного символа является его моральное наполнение; литература, проповедь, анекдоты и басни, искусство - все это имеет ценность лишь постольку, поскольку может дать человеку некий моральный урок - способствовать в конечном итоге его спасению. Чрезвычайно важно в этом смысле подчеркнуть, что именно эта трансцендентная моральная идея является конечной целью восприятия мира, текста и искусства средневековым человеком. Божественный, «скрытый» пласт реальности может быть проявлен в совершенно различных формах, поэтому один и тот же пример или описание могут отсылать к различным моральным трактовкам.

Представление о существовании трансцендентной истины приводило к тому, что форма объекта (рассказа) в средневековом мировосприятии могла иметь большее значение, чем его конкретное содержание. Именно форма, то есть те образы, которыми наполнен интеллектуальный мир Средневековья, создавали матрицу, отсылающую к надмировой божественной истине; содержание же могло быть проинтерпретировано совершенно произвольным образом. С точки зрения средневекового человека проявляющиеся в мире символы не только отсылают к трансцендентным «прототипам», но и имеют моральное значение, которое, собственно, и выходит на передний план при их трактовке.

Согласно Й. Хейзинге, средневековое понимание действительности отличается тем, что повседневная жизнь человека была до такой степени пропитана символическим религиозным содержанием, что это порождало опасность профанации религиозности. Исследователь приводит пример достаточно вольного обращения со священными символами немецкого писателя и богослова Хайнриха (Генриха) Сузо (1295-1366), «съедающего три дольки разрезанного на четвертинки яблока за Святую Троицу, а четвертую - “в любви, с коею божия небесная матерь ясти давала яблочко милому своему дитятке Иисусу”» [12, с. 258].

Подобное отношение к окружающей действительности как к требующей прочтения и истолкования «книге жизни» нашло отражение в христианской нравоучительной литературе того времени. В том числе и в нравоучительных сборниках для проповеди, которые назывались exempla.

Жак ле Гофф характеризовал exemplum как «короткий рассказ, выдаваемый за истинный и предназначенный для того, чтобы быть включенным в какую-либо речь (обычно проповедь) с целью убедить аудиторию с помощью спасительного урока» [Цит. по: 4, с. 115].

Как отмечают А. Я. Гуревич, С. Мула, В. В. Смирнова и другие исследователи, первоначально запись и изложение «примеров» не были предназначены для проповеди среди широких масс верующих. В период c XI по XII вв. ехеmpla представляли собой сборники анекдотов, описывающих не вполне обыкновенные (с вмешательством чудесного) эпизоды из жизни монахов и простых людей. Эти рассказы в основной своей массе распространялись в монашеской среде (особенно - среди монахов-цистерцианцев) и предназначались для того, чтобы предоставить братьям по ордену положительные примеры служения и поведения в рамках ордена. В ранних ехетpla указанного периода античный материал не использовался.

Стефано Мула, со ссылкой на статью Брайана Патрика Мак Гуайра, сообщает о том, что первым сборником цистерцианских exempla было «Собрание примеров и чудес Клерво», написанное между 1165 и 1174 гг. приором Иоаном [Там же, с. 117]. Помимо других эпизодов, в данном сборнике приведен случай явления Божьей Матери монахам во время сбора урожая. Цистерцианец Адам Персенский писал в одном из своих писем примерно в 1187 г. о том, что «беседа (с монахами ордена для их наставления. - К. К.) должна вестись о вещах духовных, то есть о тайнах Писания или о примерах из жизни святых. <... $>$ И это он должен проповедовать не иначе как заимствуя примеры из Священного Писания, или на собственных примерах, показывая узкую и трудную дорогу, к жизни ведущую» [Там же, с. 115-116].

Дальнейшее развитие «примеров» связано, во-первых, с их переосмыслением членами цистерцианского ордена, и, во-вторых, с рецепцией ехетрla нищенствующими орденами (францисканцами и доминиканцами) и включение их в проповедь мирянам начиная с конца XIII - начала XIV века. Важную роль в данном процессе перехода от наставления монахов в рамках одного ордена к массовой проповеди играет открытие в 1237 г. в Париже цистерцианского колледжа Святого Бернарда. В. В. Смирнова отмечает, что данный колледж, «в который отправляли монахов разных аббатств изучать теологию, можно считать символом той новой духовности, которая выводит на первый план тип ученого монаха». И далее: «При этом начиная с ХІІІ века цистерцианцы принимают все более активное участие в пастырском служении, включая проповедь мирянам» [10, с. 107]. 
Думается, мы не ошибемся, если назовем трактат цистерцианского монаха Цезария Гейстербахского «Диалог о чудесах» (“Dialogus miraculorum”), написанный в начале XIII века, одним из наиболее изученных на данный момент сборников exempla. Труд Цезария Гейстербахского предназначался для наставления братьев по ордену, однако, как показывает В. В. Смирнова, содержащиеся в трактате сюжеты и наставления в дальнейшем переосмысляются францисканскими и доминиканскими монахами и вводятся ими в собственные, предназначенные уже для проповеди сборники «примеров». Важно подчеркнуть, что в такой рецепции уже не ставится вопрос об истинности рассказываемых историй. С. Мула пишет: «Послушник, который услышал... историю от своего наставника, монах, читающий сборник, или Цезарий Гейстербахский задавались не вопросом “правдивая ли это история”, но, “что она значит для меня и для моего ордена”» [4, с. 121]. Таким образом, именно те нравственные уроки, которые возможно вынести из данных примеров-анекдотов, и становятся основной целью их распространения.

В конце XIII - начале XIV века мы уже можем говорить о проникновении в exempla античного материала. В частности, античные сюжеты используются в трактате «Римские деяния» (“Gesta Romanorum”; автор, год и место написания неизвестны, вероятно - конец XIII века, Англия или Франция). Данный трактат представляет собой сборник коротких историй-примеров с последующей аллегорической трактовкой сюжета или действующих лиц. Так, в сто пятьдесят седьмом (CLVI) «примере» автор рассказывает хорошо известную легендарную историю про то, как Ахиллес во время Троянской войны (начавшейся после похищения Елены Парисом) прятался, по наущению своей матери, во дворце царя Ликомеда, среди его дочерей, притворяясь женщиной, так как было предсказано, что, пока он жив, Троя не падет. Раскрыв данный обман, Улисс (Одиссей) снарядил в сторону царства, где скрывался Ахиллес, корабль, груженный дарами, среди которых был великолепный комплект вооружения. Ахиллес, увидев сверкающий меч, не выдержал, взял его в руку и сделал несколько изящных па. Разоблачив себя таким образом, он был взят в плен. Предлагаемая морализация такова: «Мой милый, Парис персонифицирует Дьявола; Елена - человеческую душу или весь род людской; Троя - это ад; Улисс - Христос; и Ахиллес - это Святой дух; оружие символизирует крест, ключи, копье, венок и так далее» [14, p. 334]. Мари-Анн Поло де Болье констатирует наличие влияния трактата «Римские деяния» на произведения гуманистов [8, с. 94].

«Морализация» сюжетов из античной истории и мифологии встречается во многих богословских трактатаx XIII-XIV веков, таких, как цистерцианский сборник XIII века «Млечная влага», трактат итальянского проповедника XIV века Якопо Пассаванти «Зерцало истинного покаяния», работы английского проповедника XIV века Джона Бромьярда и в большом количестве других произведений.

А. Я. Гуревич сообщает: «Нищенствующие ордена целенаправленно и с большим рвением развернули начиная с XIII века проповедническую миссию в городе и деревне» [2, с. 7]. Рассказываемые во время проповеди истории сопровождались при этом «морализациями». Кроме того, чрезвычайное значение имела яркость предлагаемых вниманию аудитории образов. Эти эффектность, наглядность и неожиданность приводимых сюжетов во многом определяли степень успеха проповеди и проповедников, лучшие из которых становились своего рода «знаменитостями», «гастролирующими» со своими лекциями о морали из города в город. Появляется новый тип проповеди - sermo modernus - проповедь для «простого народа», «популярная проповедь». Исследователь Мари-Анн Поло де Болье пишет: «Подобно большому экрану проповедь делалась “массмедиа", в особенности начиная с XIII в., когда папство решило бороться с суевериями и ересями при помощи "нового слова", доверенного специализированным орденам: нищенствующим братьям, в основном доминиканцам и францисканцам» [7, с. 151]. С помощью ярких и наглядных примеров проповедниками решались сразу несколько задач: повышение запоминаемости материала лекции (все необычное и яркое запоминается лучше, чем привычное и повседневное); разъяснение материала Священного Писания на наглядных примерах; призыв паствы к благочестивой жизни; наконец, нельзя отрицать и того, что подобные проповеди выполняли, кроме всего прочего, и развлекательную функцию. Таким образом, «визуальность - или, если угодно, образность, является важнейшим элементом стратегий, направленных на повышение эффективности проповеди» [Там же].

Для подготовки проповеди и во время нее священники прибегали к помощи различных пособий. Это могли быть как короткие нравоучительные рассказы (exempla), так и сборники библейских разъяснений (distinctiones), «которые давали для каждого ключевого слова из Библии соответствующие ему образы и краткий доктринальный комментарий» [Там же, с. 152].

Для повышения эффективности проповеди составители пособий и сами проповедники прибегали к разного рода наглядным и ярким образам. До нас дошли многочисленные свидетельства жалоб проповедников на свою паству, предпочитающую яркость повествования серьезной монотонности. Приведем только один пример: проповедник Герард Льенский писал: «Предпочитают слушать о Роланде или Оливье, нежели о Боге, и это несправедливо, ибо смерть Христа столь же драматична, как и смерть Роланда. И, однако, многие сочувствуют Роланду, а не Христу» [2, с. 70]. Широкой популярностью также пользовались легенды о короле Артуре. Судя по всему, проповедники вообще обходились со своим материалом довольно смело: все, что могло быть полезно, применялось в проповеди. Например, доминиканский проповедник XIV века Якопо Пассаванти (1302-1357) активно использовал как сочинения христианских авторов, так и античные труды. А. В. Топорова пишет: «“Зерцало истинного покаяния” (главный труд Якопо Пассаванти. $-K . K$.) свидетельствует о большой эрудиции его автора, постоянно цитирующего Ветхий и Новый Завет и ссылающегося как на христианских (Августина, Иеронима, Иоанна Златоуста, Исидора, Григория Великого), так и на античных (Платона, Цицерона, Сенеку, Теренция, Овидия, Апулея) писателей» [11, с. 39]. 
Английский доминиканский монах и составитель сборников для проповеди Джон Бромьярд (XIV век) также широко применял античный материал в своей работе. В сборнике Бромьярда "Summa praedicantium", организованном в виде своеобразного словаря, где каждому термину (такому, как «смерть» - лат. mors; «досуг» - лат. otium; «ненависть» - лат. odium) соответствует краткий комментарий автора с многочисленными примерами, достаточно часто упоминается римский стоик Сенека. Говоря о личности проповедника (praedicator) в соответствующем разделе сборника, автор замечает, что для него является недостаточным делом учить свою паству правильным вещам: прежде всего, он и сам должен выполнять то, что требует от других [13]. Данное рассуждение иллюстрируется примером из шестого письма к Луцилию: “Ad idem Seneca epistola 6 ad Lucilium. Homines amplius oculis, quam auribus credunt. Longum est iter praecepta, breve, efficax per exemplum” [Ibidem]. / «О том же [пишет] Сенека в шестом [письме] к Луцилию. Люди больше доверяют глазам, чем ушам. Путь [устного] наставления долог, краток и действенен [способ наставления] посредством [собственного] примера».

Таким образом, мы можем констатировать наличие интереса к античности среди составителей сборников для проповеди. Этот интерес, проявившийся уже в XIII веке в среде монахов-цистерцианцев, сохраняется и на протяжении XIV-XV столетий и затрагивает всю территорию средневековой Европы того времени.

O практической цели составления ехетpla заявлял еще Гумберт Романский (XIII век), который «не единожды указывал на то, что проповедник при выборе “примеров” должен руководствоваться соображениями пользы и эффективности» [8, с. 76]. Английский проповедник XIV века Джон Бромьярд также писал о том, что «ехеmplum надобен не сам по себе, а ради его значения» [Цит. по: 2, с. 23]. Таким образом, составители сборников для проповеди ориентировались на потребности рядового представителя средневекового общества своего времени. Именно этим объясняется яркость и образность приводимых в данных сочинениях «анекдотов». Как отмечает Мари-Анн Поло де Болье, «своей популярностью сборник обязан идеологической простоте содержания и скорее социальной, нежели религиозной морали, полезной для всех мирян» [8, с. 85].

Что касается использования в сборниках exempla античного материала или анекдотов из повседневной жизни, то тут самым важным обстоятельством является то, что, собственно, материал для ехетрla может быть любым: важно не то, что рассказывается, а то, какие выводы могут быть извлечены из данного рассказа. Ориентируясь на популярные в обществе сюжеты, составители сборников «примеров» включают в свои трактаты те из них, которые могут гарантировать проповеди больший успех. По нашему мнению, в этой связи нужно говорить не столько о переосмыслении античности авторами позднего Средневековья, сколько о простом заимствовании античных примеров, их присвоении в рамках существующей, чисто средневековой, парадигмы отношения к письменному тексту и к проповеди. В докладе «Монастырские сборники exempla XII-XII вв.: введение в проблематику» (2012 г.) В. В. Смирнова указывает на то, что «среди направлений, в рамках которых производится исследование (exempla. - K. K.) в последние десятилетия, преобладает так называемая “прагматика примеров”, согласно которой пример становится таковым не благодаря своему содержанию, а благодаря своей функциональности; пример - это функция... примером может стать любой рассказ, а любой сборник - сборником примеров» [9, с. 152].

Однако, говоря о прагматической составляющей средневековых сборников exempla, мы не должны забывать и о том, что «примеры» существуют в рамках специфического средневекового мировосприятия. В этой связи кажется невозможным обвинять составителей ехеmpla того времени в излишнем цинизме, «подтасовке фактов» или «подлоге». А. Я. Гуревич дает прекрасную характеристику специфики рассмотренного нами жанра: «Приводимый церковным автором пример - не самоцель. Он есть средство для внушения нравственного вывода. Тем самым единичное, анекдот, поразительный случай подводится под общее и фактическое подчинено символическому» [2, с. 333].

В качестве выводов отметим, что античные сюжеты проникают в сборники exempla начиная с конца XIII - начала XIV века. Монахи нищенствующих орденов - францисканцы и доминиканцы - активно составляли сборники «примеров», предназначенных для использования в проповеди. Красочность изображаемых сюжетов пользовалась широкой популярностью среди простого народа: легенды о короле Артуре, сюжеты из Библии, анекдоты из жизни соседствовали в проповеди с античным материалом.

Специфика отношения к античному наследию проявилась в «морализации»античной мифологии. Такая моральная трактовка символов окружающей действительности в целом была присуща миропониманию средневекового человека. В этот период окружающая действительность воспринималась в качестве «книги мира», которую необходимо трактовать в соответствии с христианским учением. Стоит заметить, что теоретическая база для подобного миропонимания была подготовлена виднейшими христианскими мыслителями, такими, как Ориген и Августин; кроме того, следует помнить, что проблема аллегорической интерпретации античной мифологии уходит своими корнями непосредственно в античность.

Говоря о прагматизме в использовании античного материала в exempla, мы, тем не менее, не должны забывать о том, что, согласно средневековому мировосприятию, смысл произведения, как и смысл любой вещи, всегда лежит за ее рамками - в божественном мире. Будучи универсальным, этот нравственный смысл всегда остается тождественен себе, так что становится неважно, в каких формах он предстает перед читателем или перед слушающим проповедь.

\section{Список источников}

1. Августин Аврелий. Христианская наука, или Основания священной герменевтики и церковного красноречия: сборник трудов и проповедей. СПб.: Библиополис, 2006. 508 с.

2. Гуревич А. Я. Культура и общество средневековой Европы глазами современников. М.: Искусство, 1989. 368 с. 
3. Корнут Луций Анней. Греческое богословие / пер. и предисл. М. М. Позднева. СПб.: Формика, 1999. 68 с.

4. Мула С. Средневековые цистерцианские exempla: между филологией и историей // Вестник Православного СвятоТихоновского гуманитарного университета. 2013. № 3 (33). С. 113-132.

5. Ориген. О началах / пер., прим. и введ. Н. Петрова. Новосибирск: Лазарев В. В. и О, 1993. 383 с.

6. Пастуро М. Символическая история европейского Средневековья / пер. с фр. Е. Решетниковой. СПб.: Александрия, 2012. $448 \mathrm{c}$.

7. Поло де Болье М.-А. Визуальные образы средневековой проповеди // Вестник Православного Свято-Тихоновского гуманитарного университета. 2014. № 3 (38). С. 151-160.

8. Поло де Болье М.-А. Сборники ехетрlа на народных языках: новая публика? Новые функции? // Вестник Православного Свято-Тихоновского гуманитарного университета. 2013. № 3 (33). С. 75-97.

9. Смирнова В. В. Монастырские сборники ехетpla XII-XIII вв.: введение в проблематику (Второе заседание научного медиевистического семинара при кафедре романской филологии, 12 декабря 2012 г.) // Вестник Православного СвятоТихоновского гуманитарного университета. 2013. № 1 (31). С. 151-154.

10. Смирнова В. В. Цистерцианские ехетрla на закате Средневековья: от истории к риторике // Вестник Православного Свято-Тихоновского гуманитарного университета. 2013. № 3 (33). С. 98-112.

11. Топорова А. В. «Зерцало истинного покаяния» Якопо Пассаванти: границы жанра средневековой проповеди // Известия Российской академии наук. Серия литературы и языка. 2011. Т. 70. № 3. С. 38-41.

12. Хейзинга Й. Осень Средневековья / сост., предисл. и пер. с нидерл. Д. В. Сильвестрова; коммент., указатели Д. Э. Харитоновича. СПб.: Изд-во Ивана Лимбаха, 2011. 768 с.

13. Bromyard J. Summa Praedicantium. Pars Secunda [Электронный pecypc]. Venice, 1586. URL: https://archive.org/details/ JohnBromyardSummaPraedicantiumParsSecunda1586/page/n561 (дата обращения: 27.08.2019).

14. Gesta Romanorum / translation Ch. Swan. L.: George Bell \& Sons, 1905. 472 p.

\title{
SPECIFICITY OF INTERPRETING ANCIENT STORIES IN MEDIEVAL EXEMPLA
}

\author{
Kislin Konstantin Borisovich \\ Saint Petersburg University \\ kislinkrel@mail.ru
}

The article examines the specificity of interpreting ancient stories in the West European medieval exempla - compilers of exempla collections for preachers. The author concludes that ancient stories were not so much re-interpreted but rather used as vivid morality tales along with other stories, such as everyday anecdotes, to secure the efficiency of a sermon. Special attention is paid to the problem of the genesis of the symbolic world perception in the Middle Ages.

Key words and phrases: exempla; medieval worldview; medieval Christian sermon; reception of ancient mythology; monastic orders.

В данной статье рассматривается переосмысление учения дзэн в виде феномена нового буддизма (представители школ Риндзай и Сотто) в рамках риторики государственной идеологии Японии, выраженной в концепции японской национальной сущности кокутай. Выявлено, что Сяку Соэн (Риндзай), Нукария Кайтэн (Со̄то̄), Судзуки Дайсэиу Тэйтаро рассматривали буддизм в его связи с этикой самураев бусидо, одной из опорных точек кониепиии кокутай, а также установлено, что наследие нового буддизма в упрощенном варианте легло в основу пропагандистского устава Сэндзинкун 1941 года, где идейные положения данных мастеров дзэн были представлены в искаженном виде.

Ключевые слова и фразы: дзэн-буддизм; новый буддизм; концепция кокутай; бусидо; японский национализм; XX век; Судзуки Дайсэцу Тэйтаро; Сяку Соэн; Нукария Кайтэн; устав Сэндзинкун.

Язовская Ольга Валерьевна, к. культурологии

Уральский федеральный университет имени первого Президента России Б. Н. Ельцина, г. Екатеринбург

Челябинский государственный университет

yazolga@gmail.com

\section{УЧЕНИЕ ДЗЭН И ГОСУДАРСТВЕННАЯ ИДЕОЛОГИЯ ЯПОНИИ ПЕРВОЙ ПОЛОВИНЫ ХХ ВЕКА}

Исследование выполнено при финансовой поддержке Российского научного фонда (проект № 17-18-01165).

Реставрация власти императора и глубокие трансформации, которые претерпевало японское общество в конце XIX - начале XX века, сделали необходимым создание определенного идеологического конструкта, который бы позволил мобилизовать массы и привести к значительному прорыву в рамках процесса 